\title{
Research Paper \\ Population Aging in Iran and Rising Health Care Costs
}

\author{
Mohammad Mirzaie ${ }^{1},{ }^{*}$ Saadallah Darabi ${ }^{1}$, Mitra Babapour ${ }^{2}$
}

1. Department of Demography, Faculty of Social Sciences, University of Tehran, Tehran, Iran.

2. Department of Economic Planning and Development, Faculty of Economics, University of Allameh Tabataba'i, Tehran, Iran.

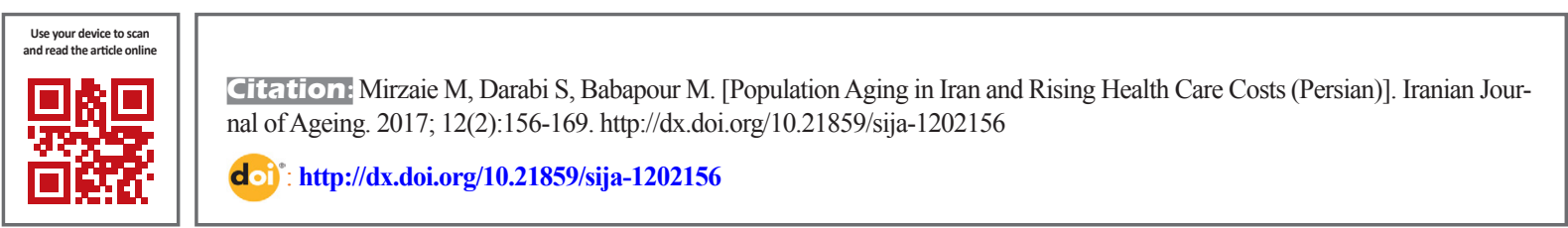

Received: 07 Mar. 2017 Accepted: 15 May 2017

Key words: Population aging, Pseudo-panel method, Life cycle, Costs of health care

\begin{abstract}
A B STRACT
Objectives This study analyzes the consumption pattern of health care costs in Iranian urban households' life cycle costs with a focus on aging period during 1997 to 2013.

Methods \& Materials This study is a secondary analysis conducted using data from the UN Population Division and household income and spending, with the help of pseudo-panel method. In order to recreate and analyze data, STATA software is used. In addition, the index of scale is used for adjusting the amount of costs relative to household size and age of people in the household, and the consumer price index is used in order to adjust inflation of the costs in different years.

Results Findings showed that the population is transitioning from youth to old age; the number of elderly is estimated to reach over 10 million people, i.e. more than $11 \%$, in 2036. Analysis of the effects of aging on health care costs show that demand for consumption from age 25 to 50 years is gradually growing; this demand then reaches its climax in the final years of an individual's life. The effect of generation showed that new generations have a higher demand for consumption of healthcare costs compared to the previous generations. The results of the study indicate that the demand for consumption is initially fixed and then is increased or decreased in the mentioned years.

Conclusion Based on the results of this research, it can be said that people throughout their life cycle always allocate a percentage of their total spending to health care costs, but the percentage of this allocation is different at different ages. In a way the demand for healthcare costs increases with aging, it rises significantly in the old age. At the macro level, due to an increase in the percentage of elderly in the population over the next decade, there will also be an increase in the share of health care costs.
\end{abstract}

\section{Extended Abstract}

\section{Objectives}

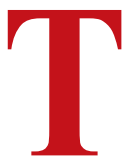

his study aimed to analyze consumption patterns of health care costs in the life cycle of urban households in Iran with an emphasis on old age during the years 1996 to 2011. Since the age structure of the population is moving towards aging, explaining the social, economic, and health concerns of the aging population and its consequences is necessary. This further requires searching for appropriate solutions and more accurate planning in connection with the issue of the old people. In this study, we studied the aging population of Iran while analyzing the consumption patterns of health care costs in the life cycle of urban households with an emphasis on old age. With the help of its findings, a perspective is presented regarding the consumption demand in this cost area in the coming years given the

\section{* Corresponding Author:}

Saadolah Darabi, PhD Candidate

Address: Department of Demography, Faculty of Social Sciences, University of Tehran, Tehran, Iran.

Tel: +98 (919) 5354248

E-mail: darabi1398@yahoo.com 
demographic transition towards old age in Iran in the near future.

\section{Methods \& Materials}

In this secondary analysis, the average data reviewed and published in 2015 by the Population Division of the United Nations (UN) has been used to predict the population aging trend. The reference for registering mentioned data is validated at the national level collected through civil registration system, sample survey, and census. This organization collected the latest information on age and sex structure of the population in different countries and used them to predict the size and composition of the population of each country at various time intervals.

For population prediction until 2050, the Population Division of the UN employs assumptions regarding future trends in fertility, death, and international migration. As future trends cannot be conclusively determined, various forecasts were made based on assumptions. Given the current trend of fertility in Iran and opinion of experts, the assumptions about Iran's population is considered to be more realistic and is considered the standard practice. Next, the consumption pattern of health care costs in the life cycle of urban households in Iran, especially during old age, was analyzed using the cost of household income with the help of the pseudopanel method and STATA software.

The data used in this section is raw census data regarding the economic and social characteristics of urban households collected by the Statistical Center of Iran during 1996 to 2011. Statistics of Household Expenditure and Income Plan in 1962 was carried out with the aim to access the household budget structure. In this plan, the main focus is on costs along with questions related to household spending. Information will also be asked about individuals' and families' income. This data was collected and registered at intervals of one year using a sample survey by visiting sample households in urban and rural areas.

\section{Results}

According to this study, the percentage of people older than 65 years in Iran will be more than 4 million (10\%) in 1414 (2035) and more than 19 million in 1429 (2050). The comparison of the average total cost and healthcare costs of households with elderly family head from 1996 to 2011 showed that the share of health care costs from the total household expenditure steadily increases. According to a fixed percentage of the old population in Iran during the study, this mostly results due to the increase in life expectancy of the old people, financial burden of diseases of old age, and paying more attention to health care and treatments at the family and society levels.

The comparison of health care costs of urban households showed that the new generation has higher consumer demand in the field of health care costs such that slope of the curve in new generations is significantly increasing. The arrival of new generations may affect the increased demand in this field from different aspects such as increasing number of generations, lifestyle changes and technological progress, increasing education levels, trends in urbanization, and urban households having health care services. Results showed that the effect of age on the demand for health care costs from the age of 25 years is rising. This increase, especially from age 60 years onwards, takes a very sharp slope due to the financial burden of old age diseases and associated costs.

Results of the effect of the demand for health care costs indicate that during the study period, consumer demand in this sector was variable under the impact of government policies and economic performance. Consequently, the level of income and the purchasing power of the people, in a way that consumer demand trends are relatively constant over the period from 1998 to 2002 and during 2003 to 2007, showed a sharp fall. Then, in 2007, 2008 and 2009, consumer demand increased steeply, but during the years 2011 to 2012, this curve fell sharply. This dramatic decline in recent years is related to a significant increase in exchange rate and inflation and reduction in the purchasing power of people.

\section{Conclusion}

Based on the results of this study, it can be said that people during their life cycle allocate a percentage of their total costs to health care costs but this percentage of allocation is different at different ages such that it increases in old age. Demand in health care costs also significantly increases. With regard to the pattern of these changes at the micro level (individual and family) and its extension to the macro level (society), it can be concluded that due to the change in age structure in Iran in the next few decades and a significant increase in the proportion of old people in the population, the health care sector will be costly in the future far more than the current situation. Moreover, its consumption patterns 
will be changed, and thus, the need for a coherent planning in this context is necessary.

\section{Acknowledgments}

This research was extracted from the MA thesis of the second author in the Department of Demography, Faculty of Social Sciences, University of Tehran, Tehran.

\section{Conflict of Interest}

The authors declared no conflicts of interest. 


\title{
سالخوردتى جمعيت در ايران و هزينههاي رو به افزايش بهداشت و درمان
}

\author{
محمد ميرزايى'، "سعداله دارابى'، ميترا بابايور' \\ 1- كروه جمعيتشناسى، دانشكده علوم اجتماعى، دانشعاه تهران، تهران، ايران.

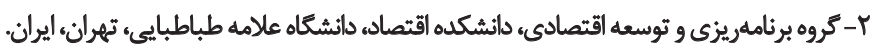

\section{حكبد}

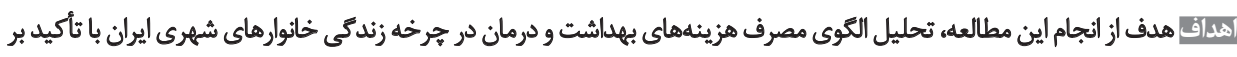

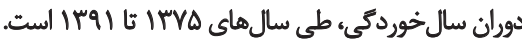

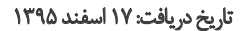

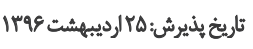

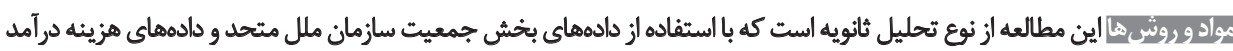

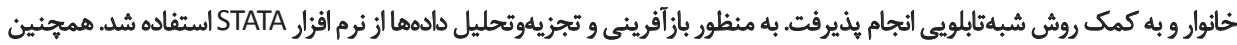

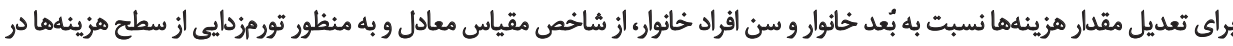

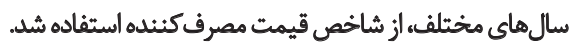

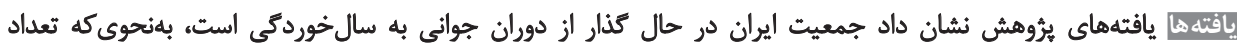

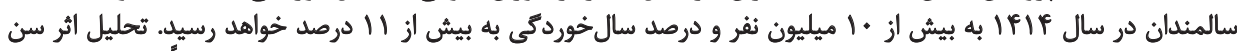

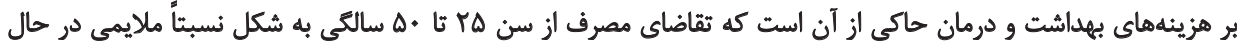

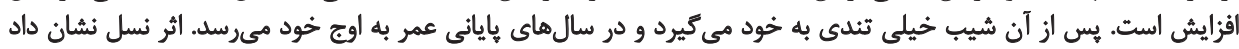

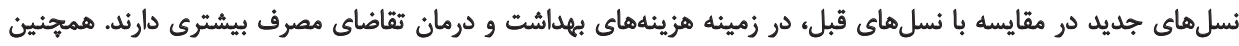

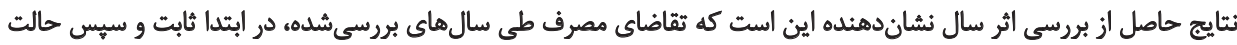
افزايشى و كاهشى داشتئه است.

كليدوأزهوا:

سال خوردكى جمعيث، روش سالتردي

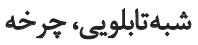
زندئى، هزينهائهاي بهاشتئى درمانى هزين

هزينهاي بهداشتى درمانى سرسامَآور و غيره ازجمله مواردى

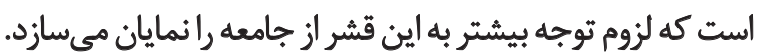

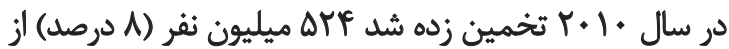

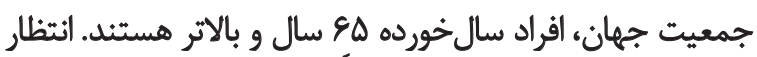

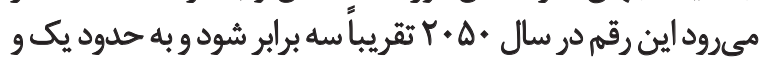

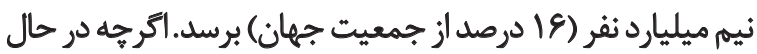

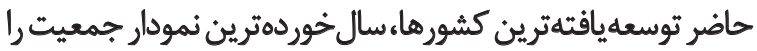

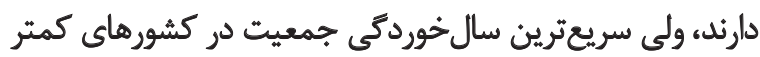

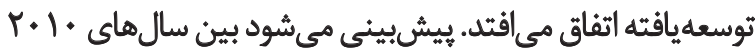

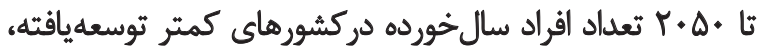

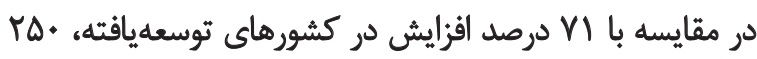

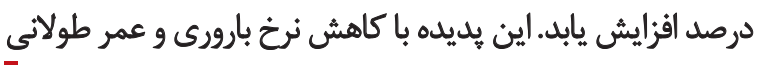

طى ينجاه سال اخير توسعه اقتصادىاجتماعى، كاهش بارورى

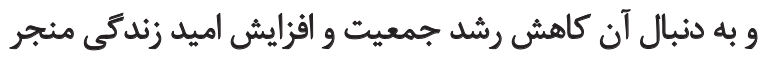

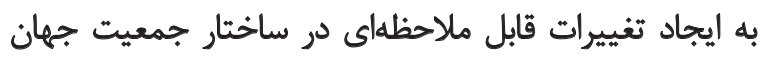

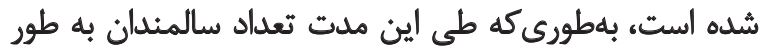

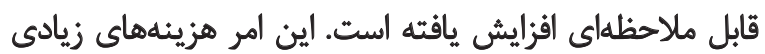

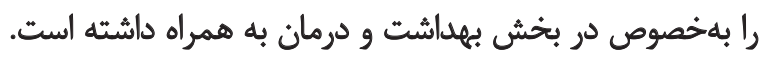

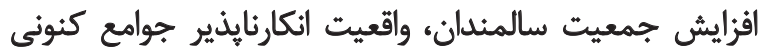

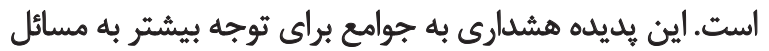

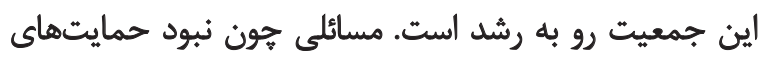

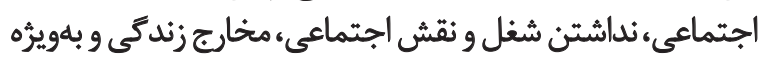

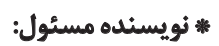

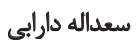
نشائي: تهران، دانشكاه تهران، دانشكده علوم اجتماعي، كروه جمعيثشئاسى. تلفن: يست الكترونيكي: darabi1398@yahoo.com 
مطابقت دارد [س].

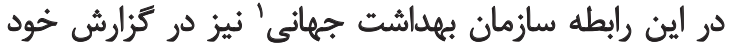

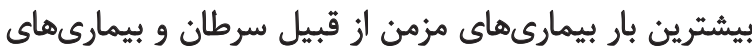

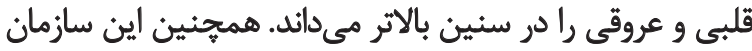

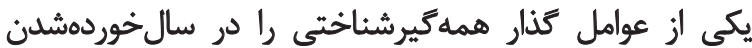

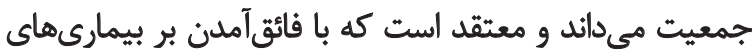

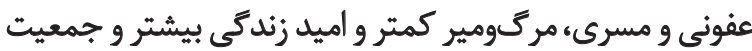

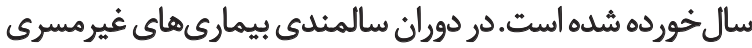

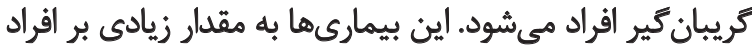

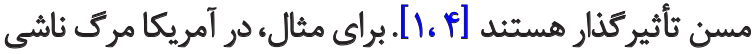

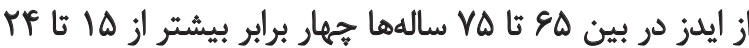

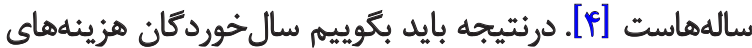

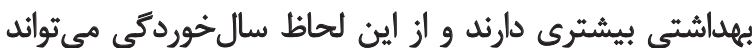

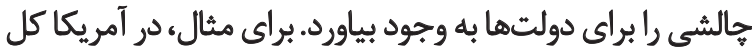

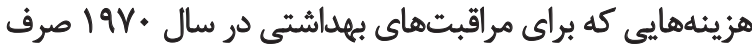

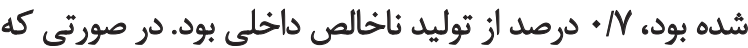

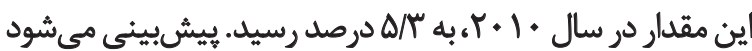

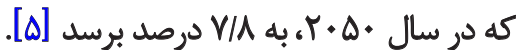
مطالعات اندكى در زمينه الكوى سنى هزينههاى بهداشت و

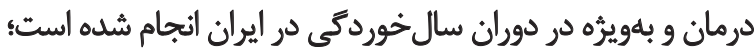

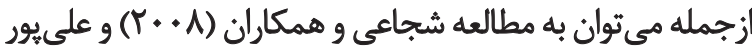

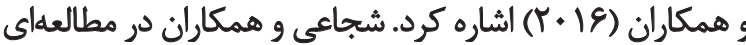

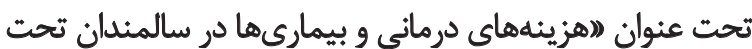

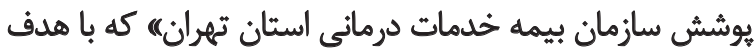

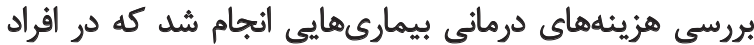

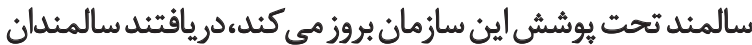

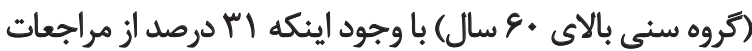

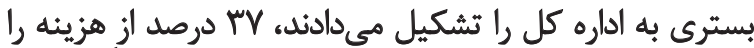

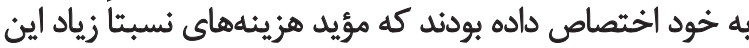

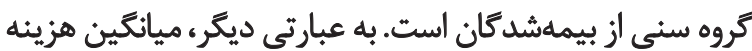

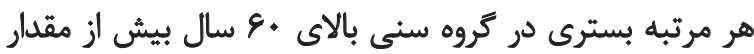

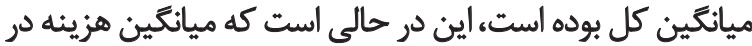

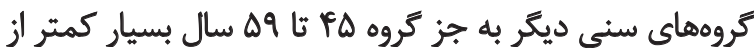

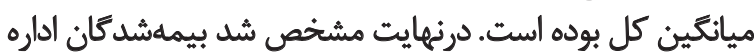

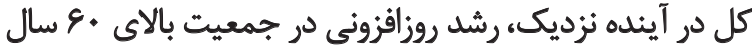

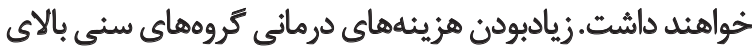

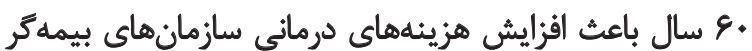

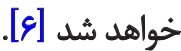

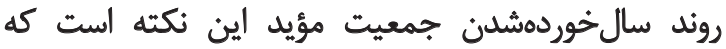

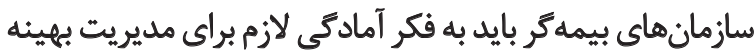
منابع باشند. علىيور و همكاران در مطالعهايى با عنوان لاتحليل

1. World Health Organization (WHO)
شكل ترفته است. با كاهش تولد و افزايش طول عمر، سهم افراد سال خورده از كل جمعيت در حال افزيش ايش است [1 [1]. جمعيت ايران نيز در حال حاضر در مرحله انتقال ساختار

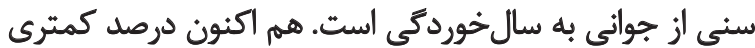

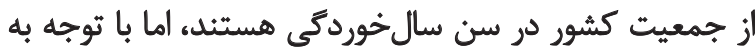

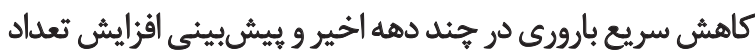

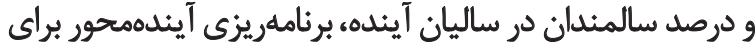

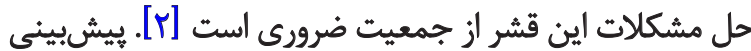

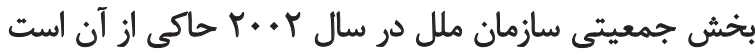

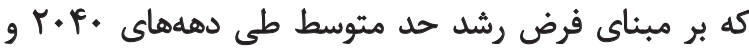

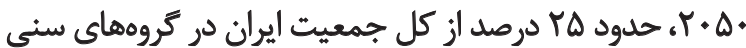

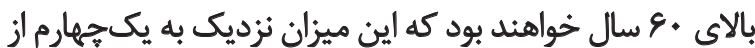

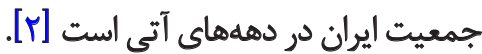

بر اساس نتايج مطالعات انجام شده در اين زمينه، در حال

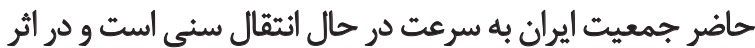

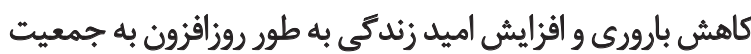

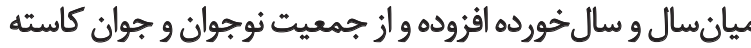

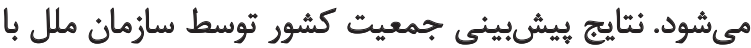

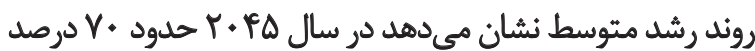

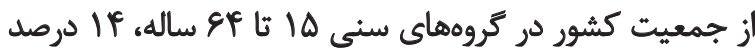

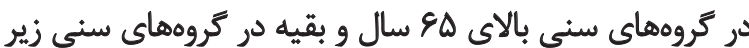

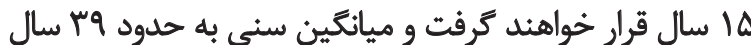

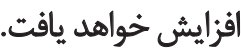

بررسىها نشان ميدهد در سال ITVD

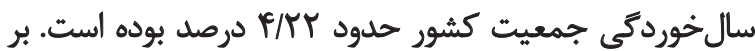

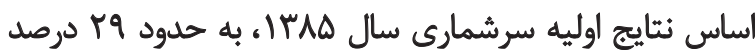

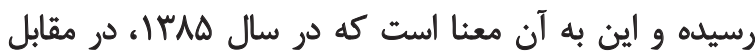

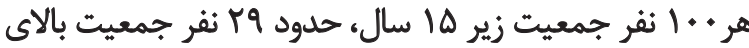

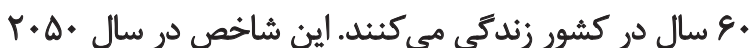

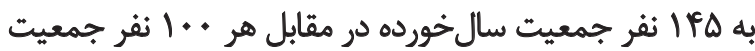

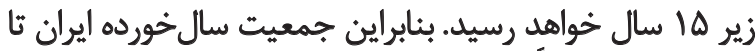

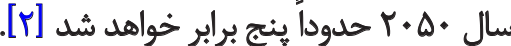

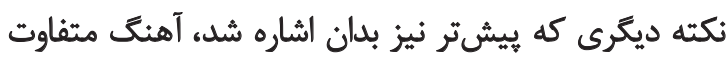

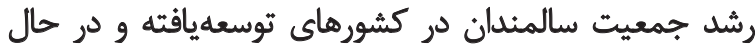

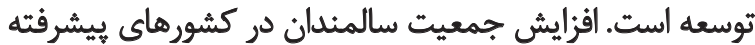

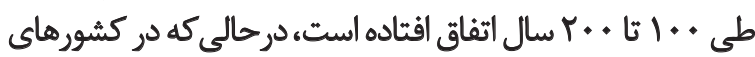

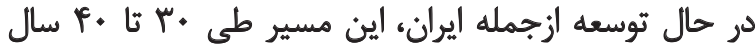

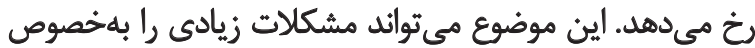

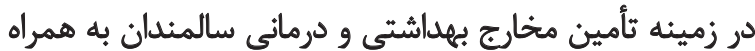

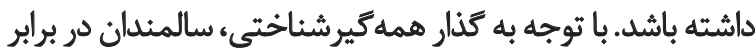

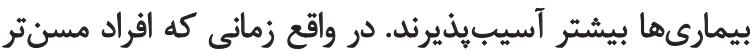

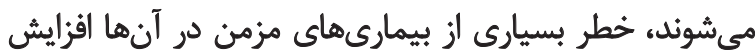

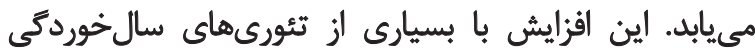


از طريق سيستم ثبت احوال، بررسىهاى نمونهاى (ييمايشها)

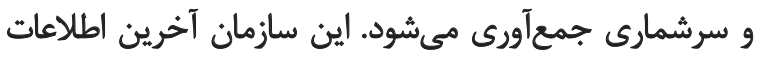

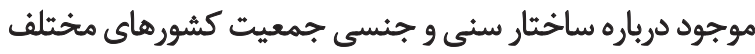

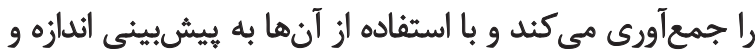

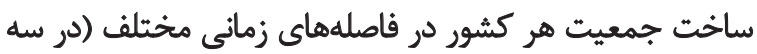
سناريو، فرض متوسط و بالاو و پايين) مى بيردازد.

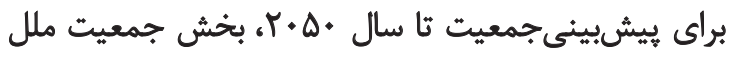

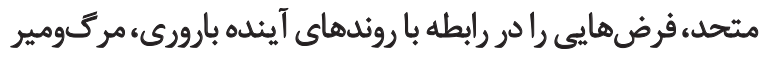

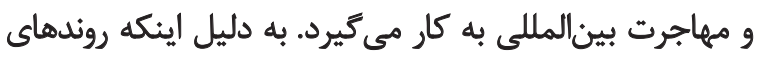

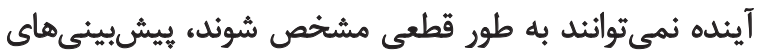

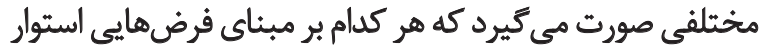

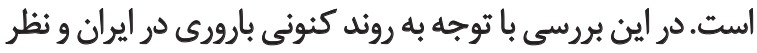

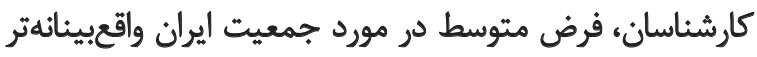

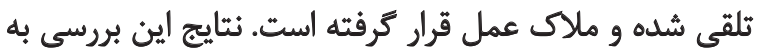

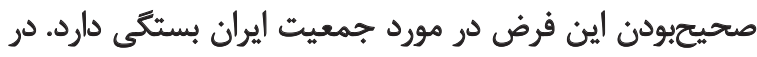

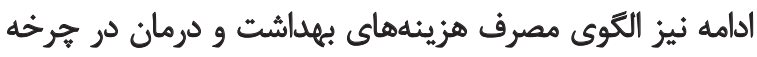

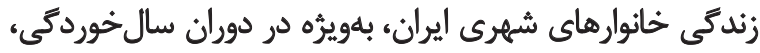

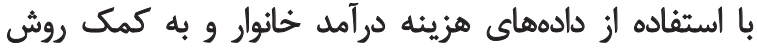
شبهنابلويى [9] تحليل شده است.

دادههاى استفادهشه در اين بخش، دادهماي خام خام طرح

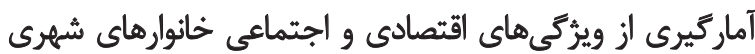

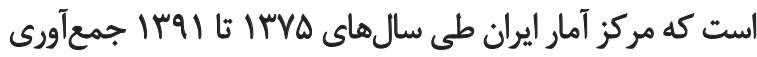

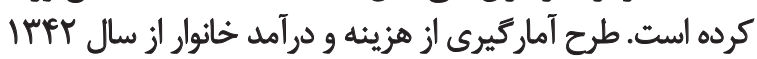

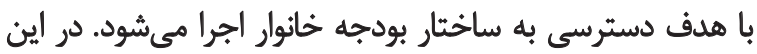

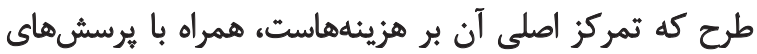

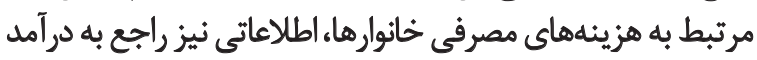

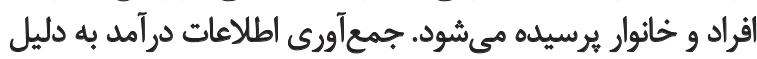

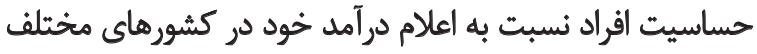

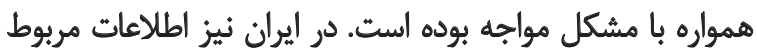

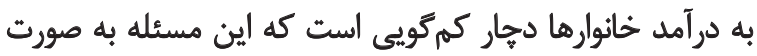

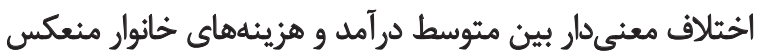

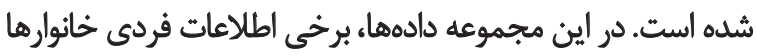

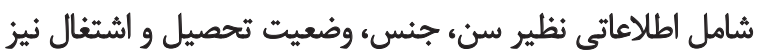

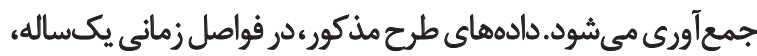

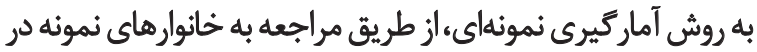

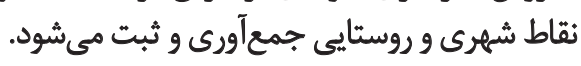

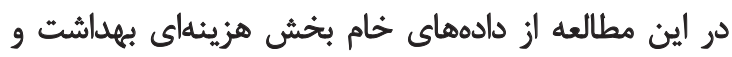

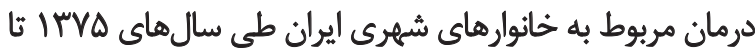

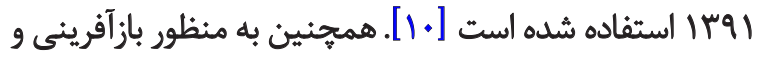

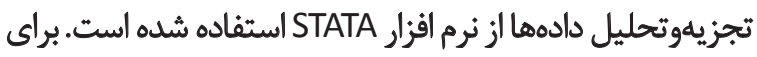

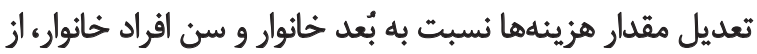

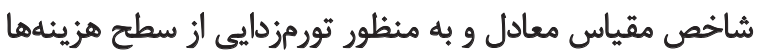
در سال هاى مختلف، از شاخص قيمت مصرف مُكنئده استفاده شد.
هزينههاى درمانى سال هاى خايانى عمر با رويكرد فاصله زمانى

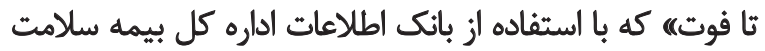

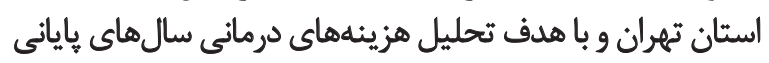

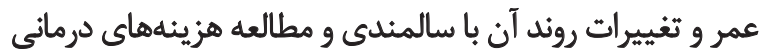

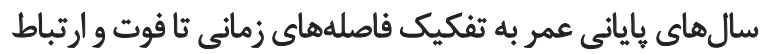

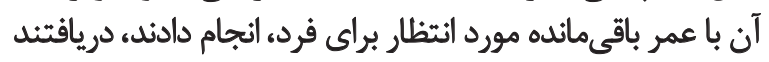

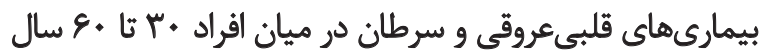

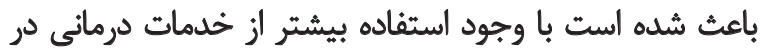

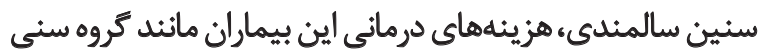

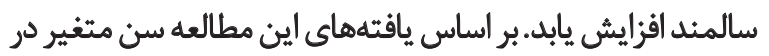

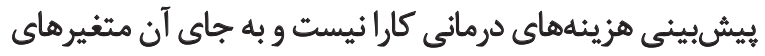

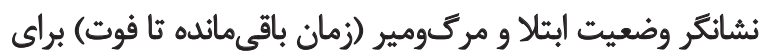

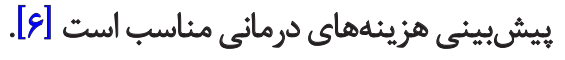
درمجموع مىتوان كفت افزايش طول عمر و اضافهشدن

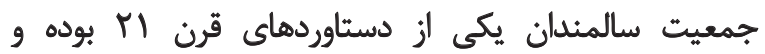

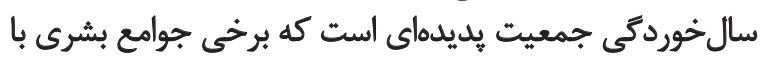

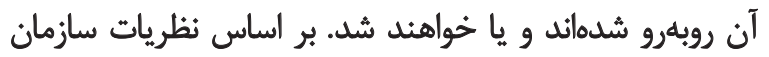

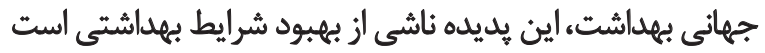

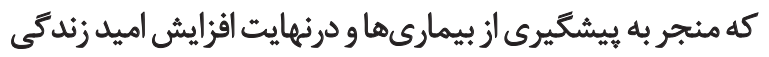

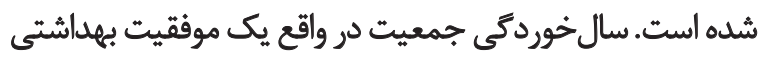

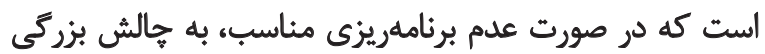

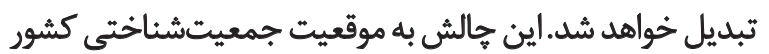

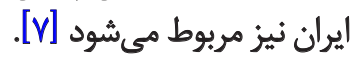

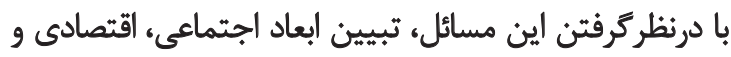

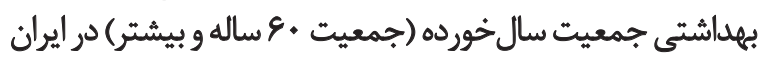

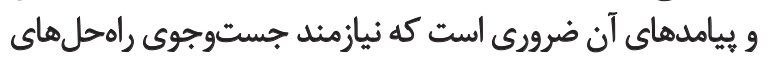

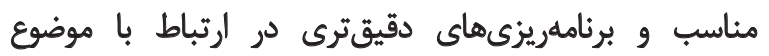

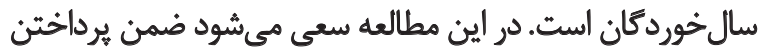

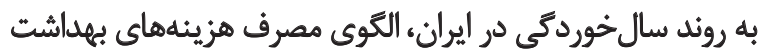

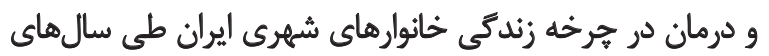

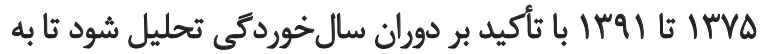

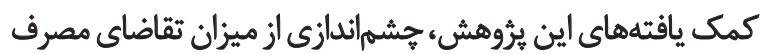

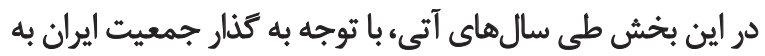

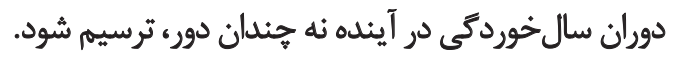

$$
\text { روش مطالهه }
$$

اين مطالعه از نوع تحليل ثانويه است. براى بيشيشينى روند

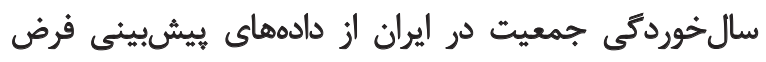

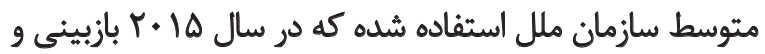

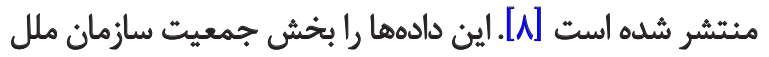

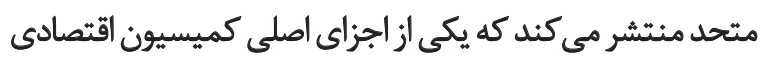

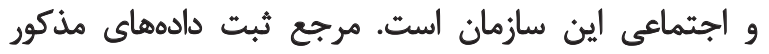
دادههاى معتبرى است كه در سطح ملى (كشورهاى مختلف) فئ ادهاي 
تقسيم جمعيت بالاى \$ \& سال به كل جمعيت به دست مي آيد.

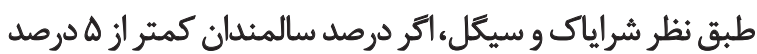

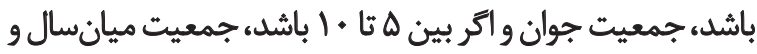

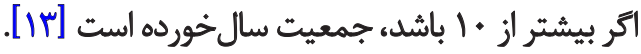

جدول شماره ا نتايج فراوانى و درصد جمعيت 9ه سال و بيشتر

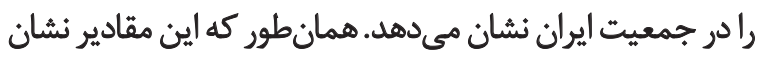

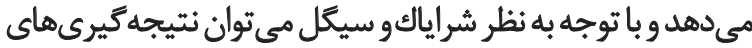

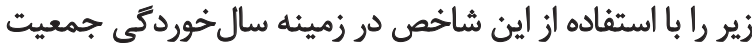

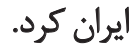

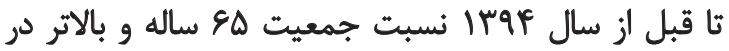

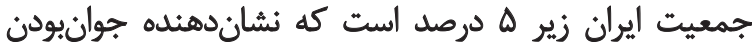

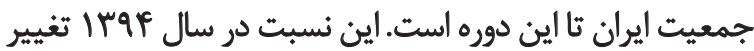

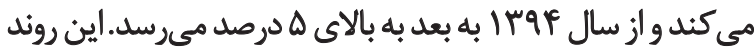

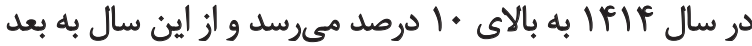

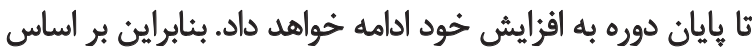

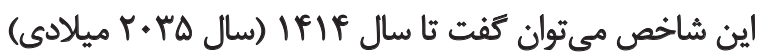
جمعيت ايران، ميانسال و پيس از آن سال خورده ميشان آشود. تعداد سالمندان در جمعيت مىتواند در برنامهريزيها بسيار

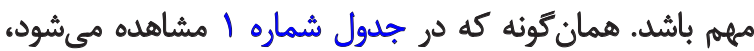

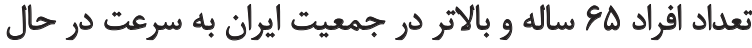

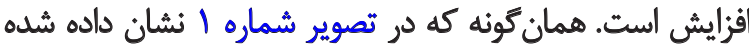

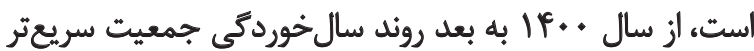

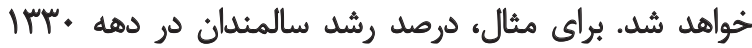

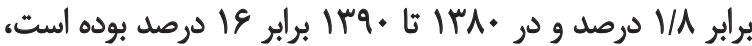

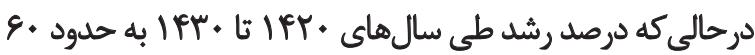

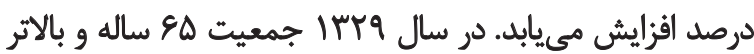

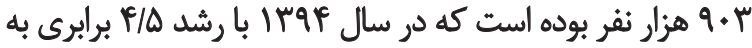

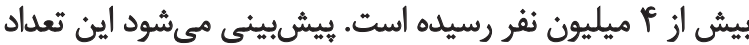

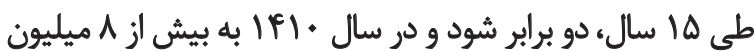

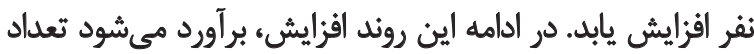

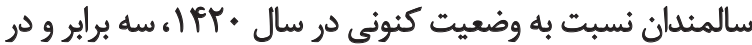

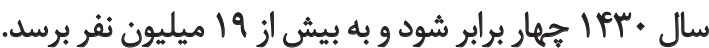

$$
\text { ارزيابى الكّوى مصرف هزئههاى بهدأشتى دمائى }
$$

يافتههاى تحقق حاضر حاكى از وزن بالاى گروه بهداشت

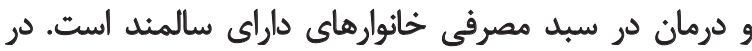

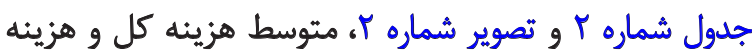

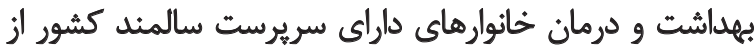

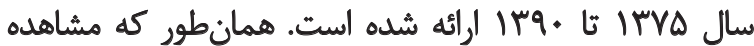

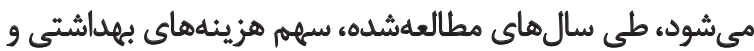

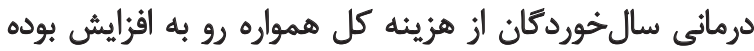

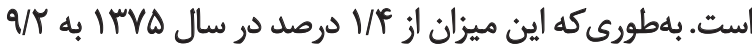

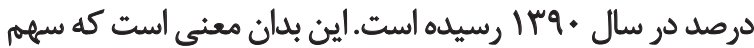

رويكرد نسلى و دادههاى شبلثنابلويى

ازجمله مسائل مهمم مطالعات يويا در رابطه با اندازهيرى،

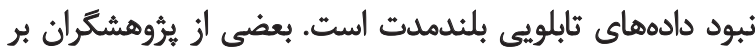

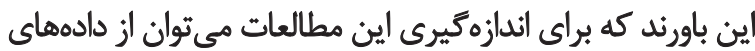

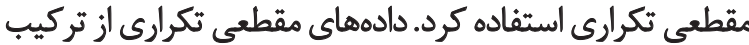

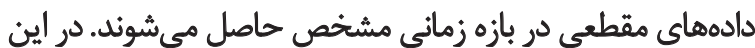

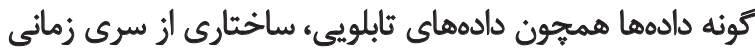

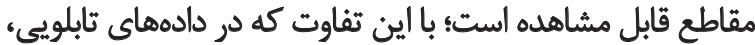

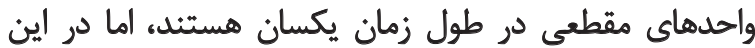

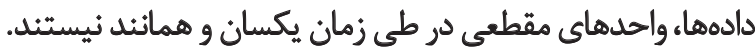

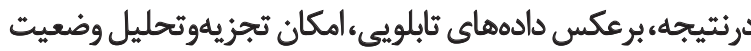

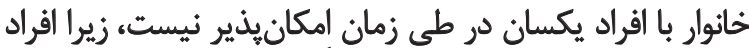

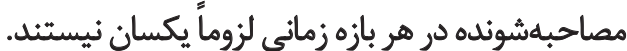

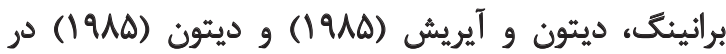

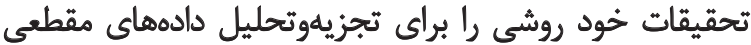

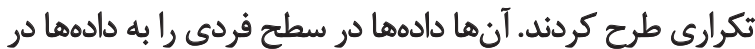

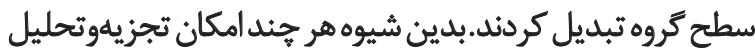

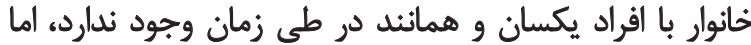

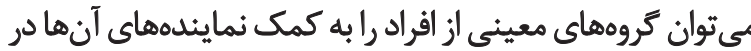

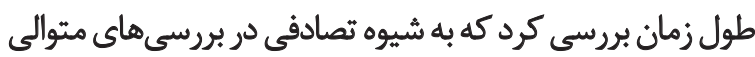

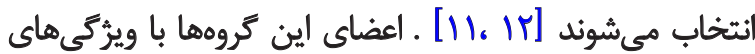

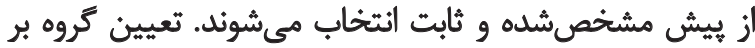

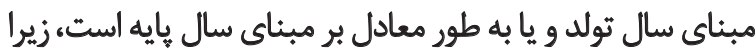

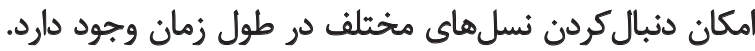

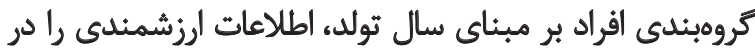

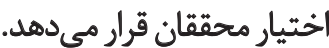

ديتون (19 (1) بر اين باور است كه در صورت در اختيار نداشتن

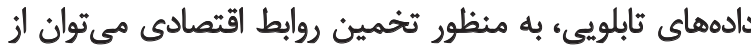

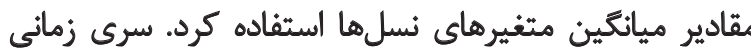

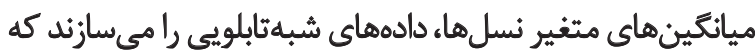

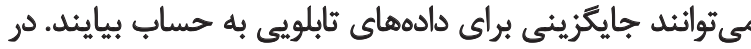

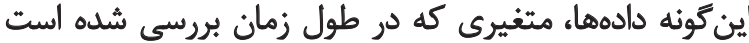

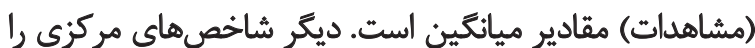

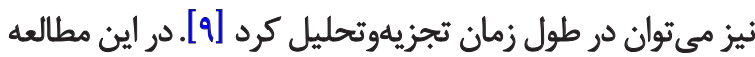

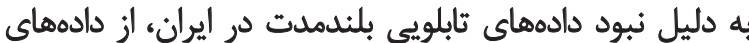
مقطعى تكرارى (شبهتابلويى) استفاده شده است.

يافتهها

ارئابي روند سال خوردكّى جمعيت درايران ثا سال + + با توجه به اينكه معمولاً به افراد هاع سال به بالا سال خورده

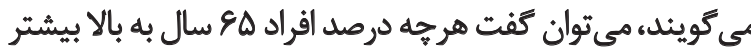

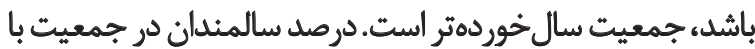




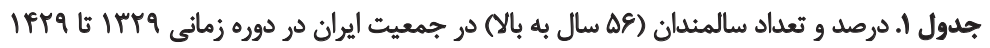

\begin{tabular}{|c|c|c|c|}
\hline سال (هجرى شمسى) & تعداد (به هزار نفر) & درصد & سال (ميلادى) \\
\hline IrTa & $q . r$ & $\Delta / N^{\infty}$ & 190. \\
\hline קוm & 9Tा & $P N$ & $19 \Delta \Delta$ \\
\hline 1rraq & 97. & $\%$ & 198. \\
\hline ImfF & 919 & $\Gamma / \Delta$ & 1980 \\
\hline irfeq & 1.158 & $r / \mu$ & $19 \mathrm{~V}$. \\
\hline Iraf & $11 \mathrm{n}^{\prime}$ & $r / r$ & I9VD \\
\hline 1709 & $|r|$. & $\%$ & 144. \\
\hline Irese & $1 Q 4$. & $r / 9$ & 140 \\
\hline Irea & IAIV & $r / \mu$ & 199. \\
\hline $1 \pi r^{e}$ & rAAT & $r / \Lambda$ & $199 \Delta$ \\
\hline irva & mlif & $P / r$ & r... \\
\hline IrAP & rose & $p / q$ & $r+\infty$ \\
\hline $1 \% 19$ & reiv & $f / q$ & $r+1$. \\
\hline $1+99$ & $f++8$ & $\Delta / /$ & $r+10$ \\
\hline 11999 & fqur & $g / N$ & r. T. \\
\hline $1 f+F^{f}$ & GFY & $V / A$ & $r \cdot T \Delta$ \\
\hline $16=9$ & Alwe & $9 / N$ & T.T. \\
\hline lfiff & $1 . . r \Delta$ & $11 / A$ & T.ro \\
\hline Ifig & 1188 & $1 \% / q$ & r.f. \\
\hline IFTP & IPVer & $|v /|$ & $r \cdot P \Delta$ \\
\hline 1149 & 19.8. & $\mathrm{rY} / \mathrm{.}$ & $r \cdot \Delta$. \\
\hline
\end{tabular}

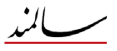

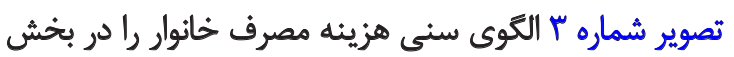

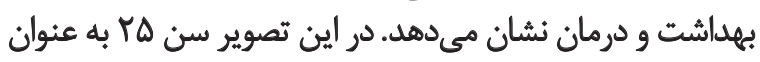

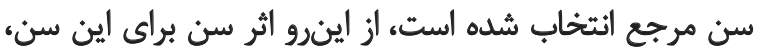

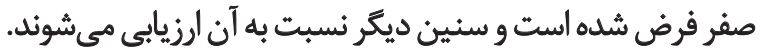

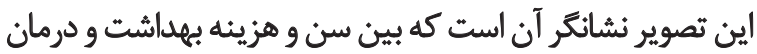

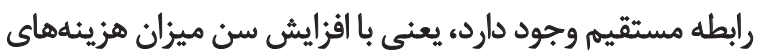

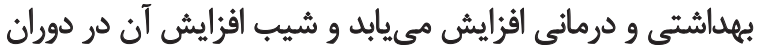

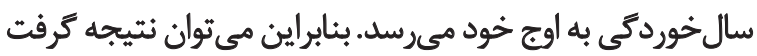

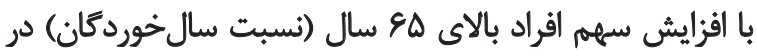

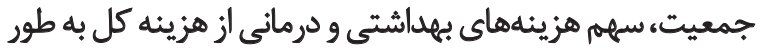

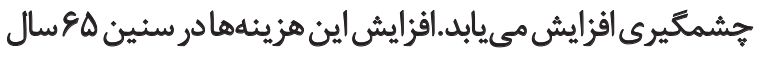

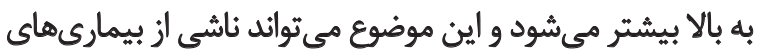

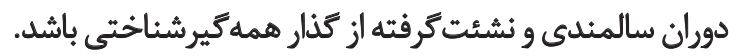

هزينه بهداشت و درمان براي سالمندان بيش از 9 برابر افزايش

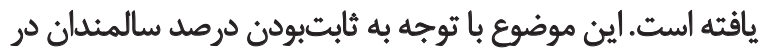

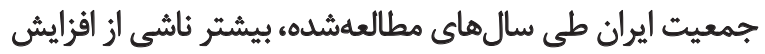

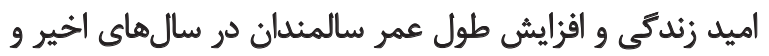

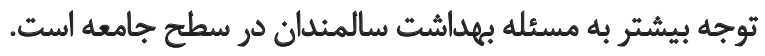

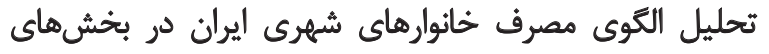

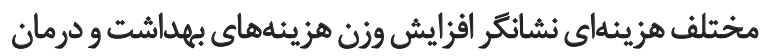

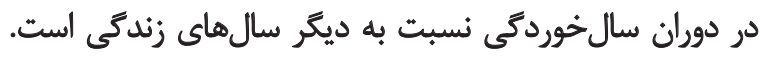

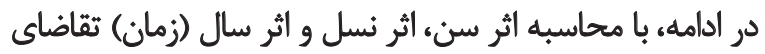

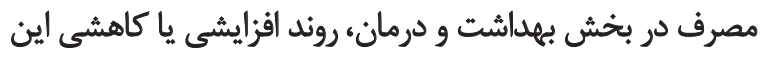

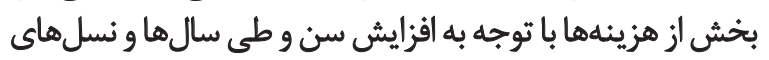
مختلف ارزيابى مي ازئودا 


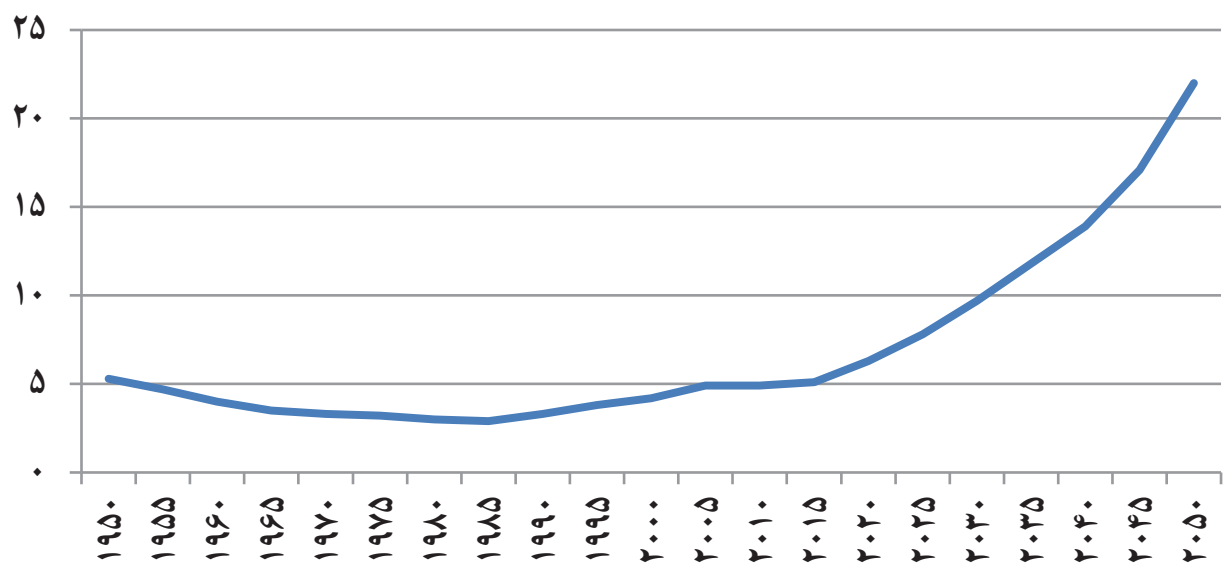

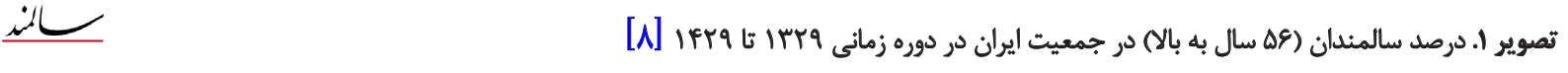

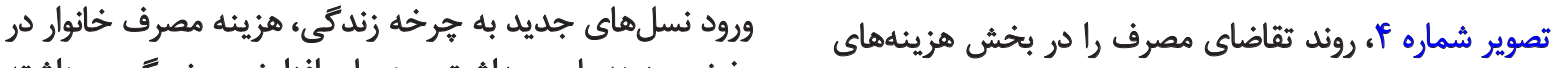

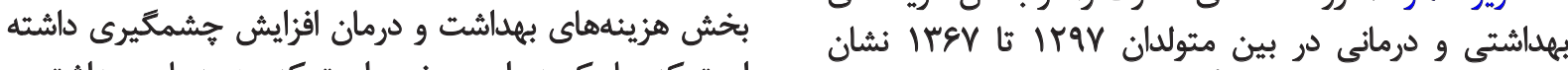

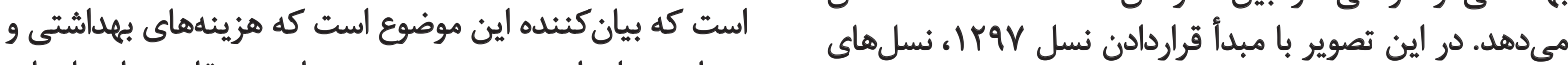

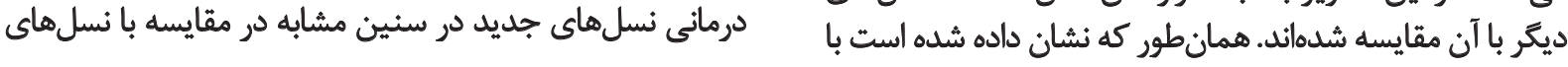

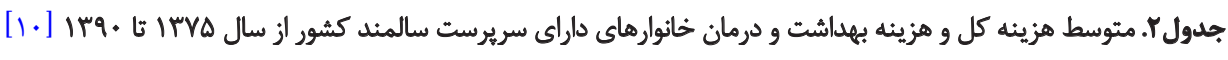

\begin{tabular}{|c|c|c|c|}
\hline سيهم هزينه بهداشت و دومان از هزئه كل & ميانكَين هزينه بهباثشت و درمان & ميانكين هزينه كل (سالاثه) & سال \\
\hline$\% /$ & MTIMA & A. QPATq & ITVO \\
\hline$r / \mu$ & Prole. & $1.11+\ldots$ & Itrve \\
\hline$F / V$ & $\Delta A T \Delta A F$ & IMFIESA. & IrW \\
\hline$r / 8$ & garvaq & $|Q+A| V \mid V$ & Irva \\
\hline$r / 8$ & VE八Q9 & IEVIEVIV & $17 v 9$ \\
\hline$F / A$ & 9YNF.1 & $19 \Delta \Delta \ldots$. & IrA. \\
\hline$\Delta / 1$ & ir.preq & rTEYTAYq & $|r A|$ \\
\hline$\Delta / \Gamma^{\top}$ & $1 \Delta V \Delta \Delta \cdot V$ & PQVTEDFY & IrAY \\
\hline$V N$ & mTral & $r e+1 \cdot r r$ & IrAN" \\
\hline V/e & rq9०ท। & rapinteq & IrAf \\
\hline$V / A$ & MERATA & PHT. TMF & IrAs \\
\hline$N)$ & FIrorea & $\Delta 1+\Delta M M$ & IHA \\
\hline Nq & DrardVF & $\Delta q+$ YAqT & IHAV \\
\hline $9 / 4$ & $\Delta 1 \Delta \Delta .9 F$ & STrAVII & ITM \\
\hline$q / r$ & gQRTIVA & VAFA99VA & Irk9 \\
\hline $9 / r$ & q.merter & Q11AQ9.. & $1 \% q$. \\
\hline
\end{tabular}

ن 


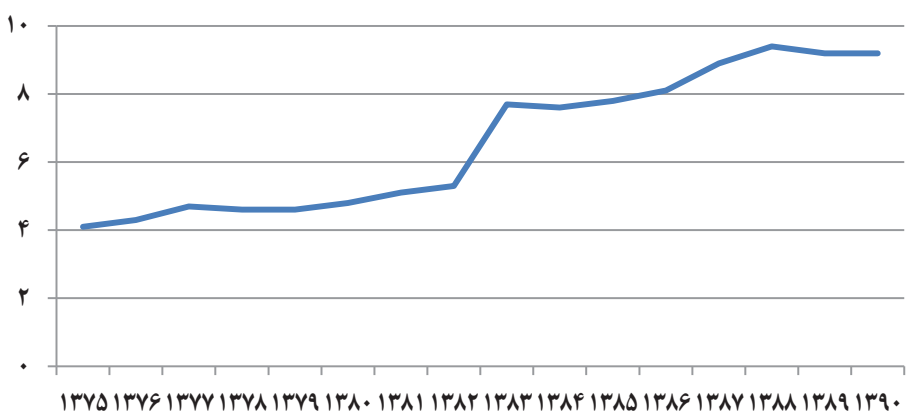

L

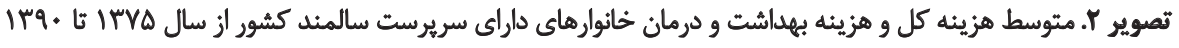

دانست. بنابراين يكى از دلايل سقوط مى تواند ناشى از افزايش

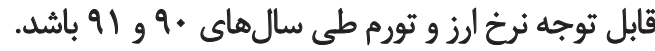

مىتوان جنين نتيجه كرفت كه تقاضاى مصرف در بخش

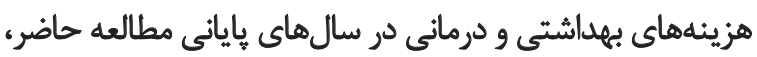

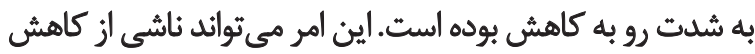

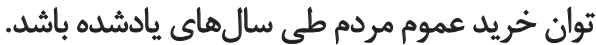

ثب

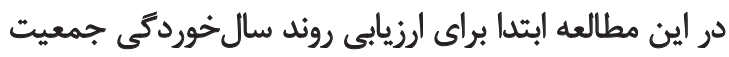

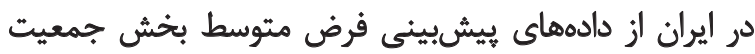

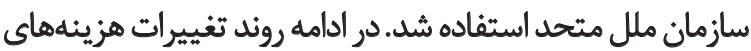

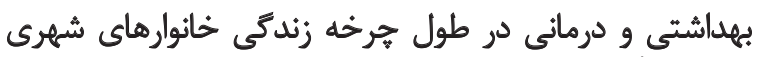

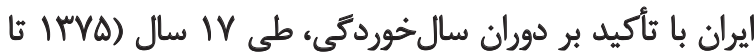

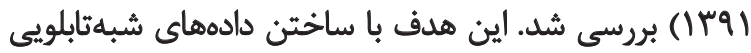

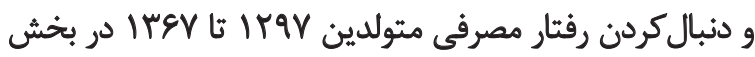

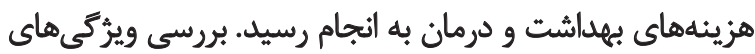

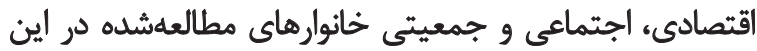

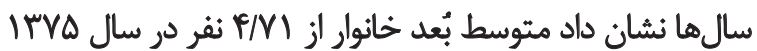

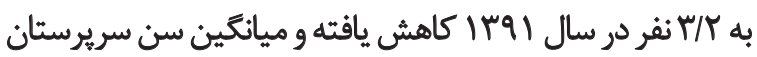

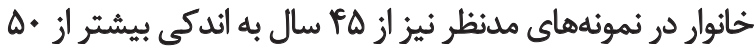

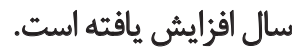

اين درحالى است كه وضعيت زناشويى خانوارهاى شهرى

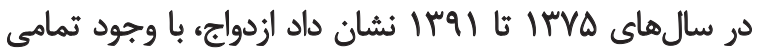

كذشته افزايش جشمكيرى داشته است.

البته بايد توجه داشت شيب زياد منحنى در نسلهاى جديد جديد

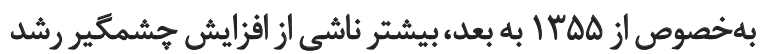

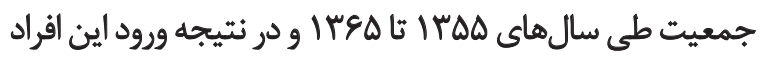

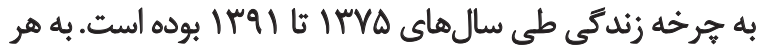

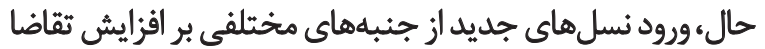

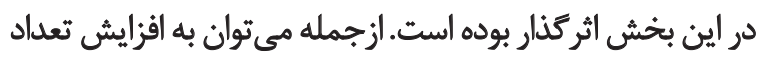

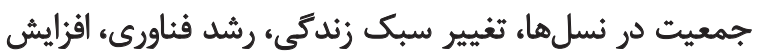
سطح سواد و ميل به شهرنشينى اشاره كرد.

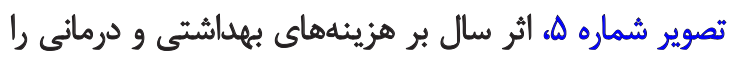

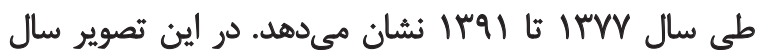

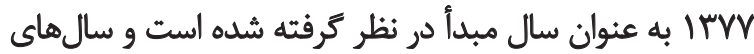

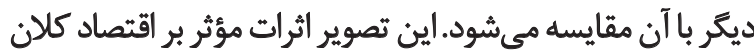

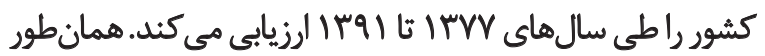
كه ملاحظه مي

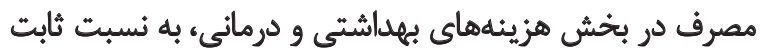

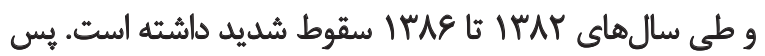

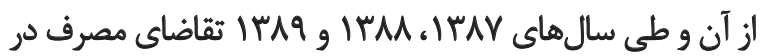

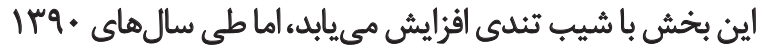

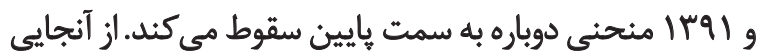

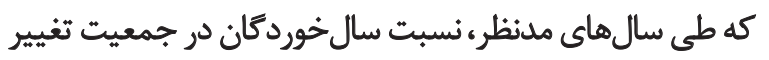

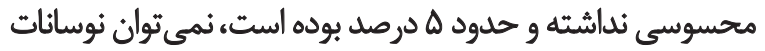

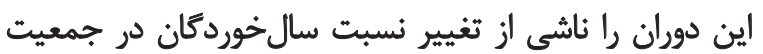

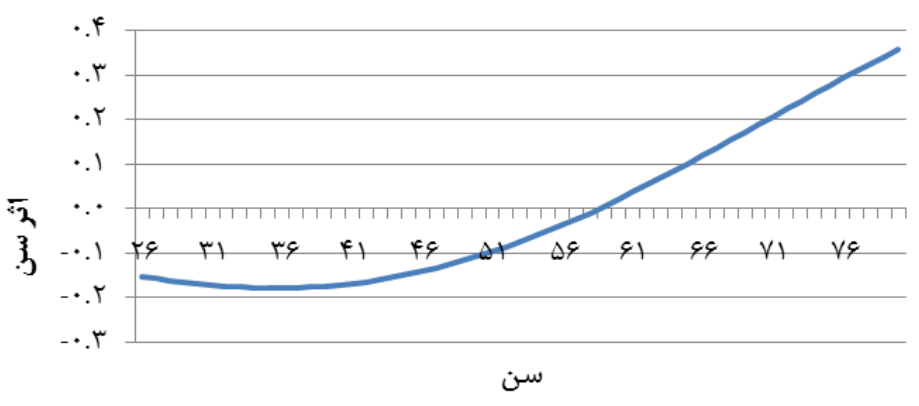

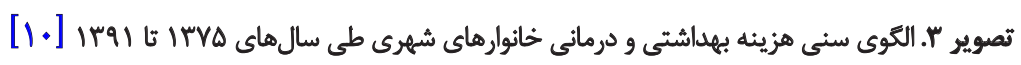




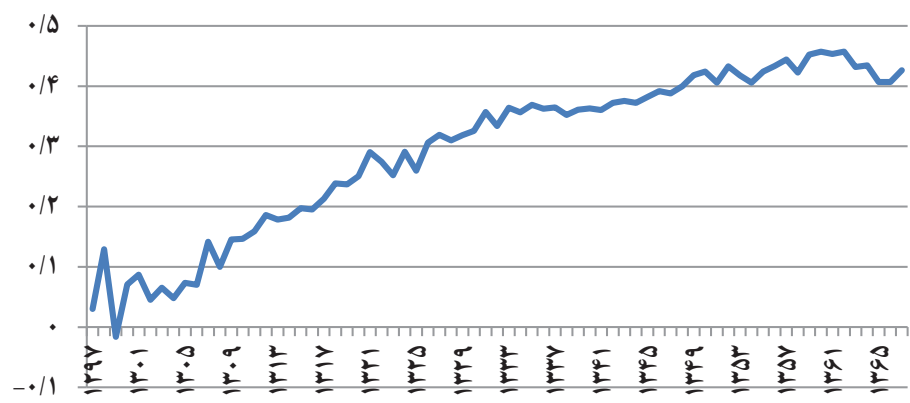

L

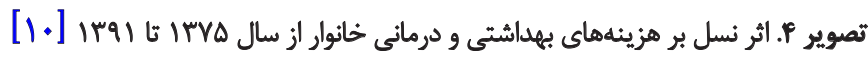

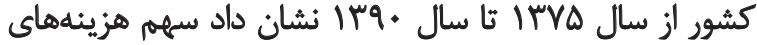

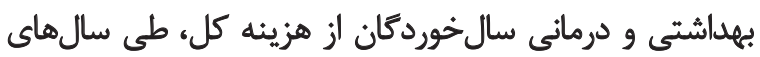

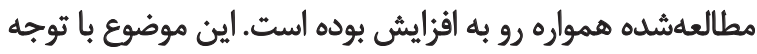

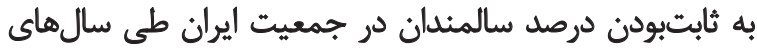

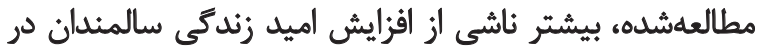

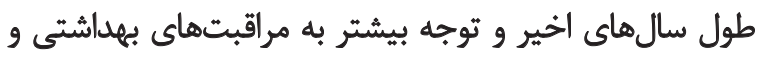
درمانى آنها در سطح جامعه است.

مقايسه هزينهاي بهداشتى و درمانى خانوارهاى شهرى به

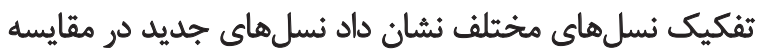

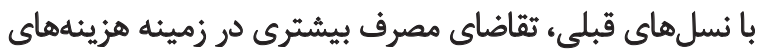

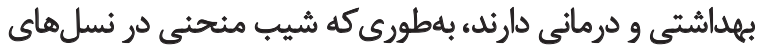

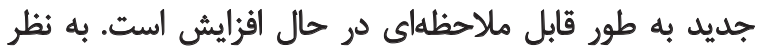

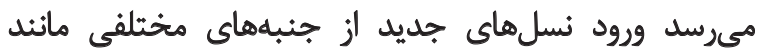

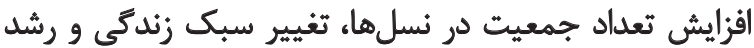

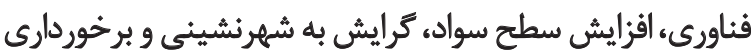

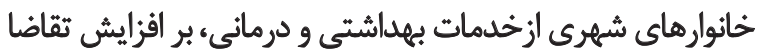
در اين بخش اثركذار بوده است.

نتايج مربوط به اثر سن نشان داد اثر سن بر تقاضاى مصرف

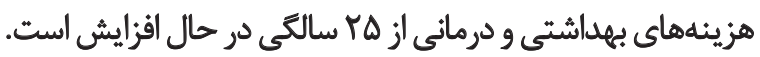

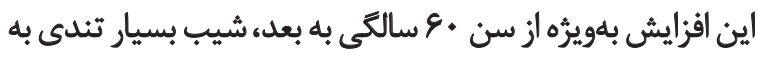
خود مى
بيامدهاى اقتصادىاجتماعي، در كذر زمان همجئنان اهميت

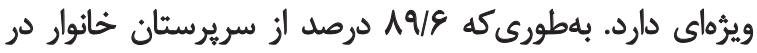

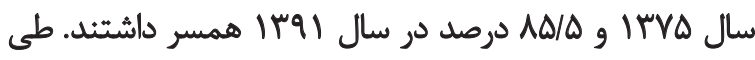

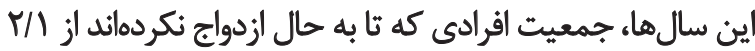

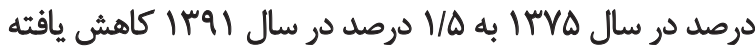

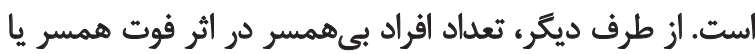

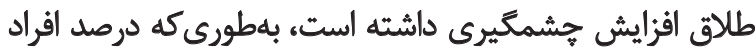

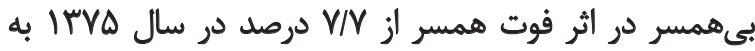
11/A درصد در سال |

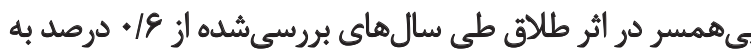
ا 1/ درصد (دو برابر) افزايش يافته است.

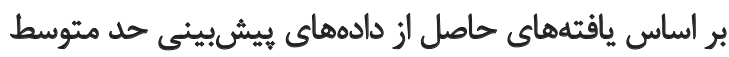

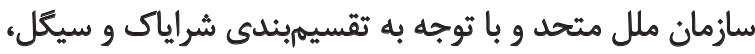

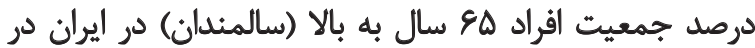

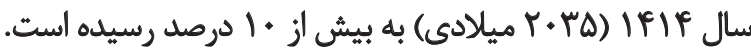

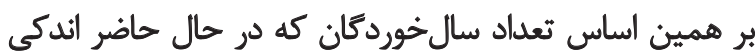

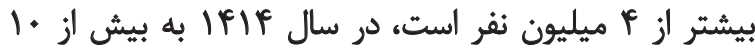

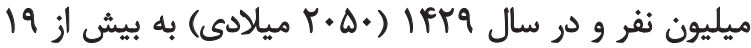

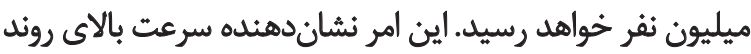

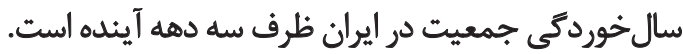
مقايسه متوسط هزيئه كل و هزينه بجداشت و درمان سالمندان

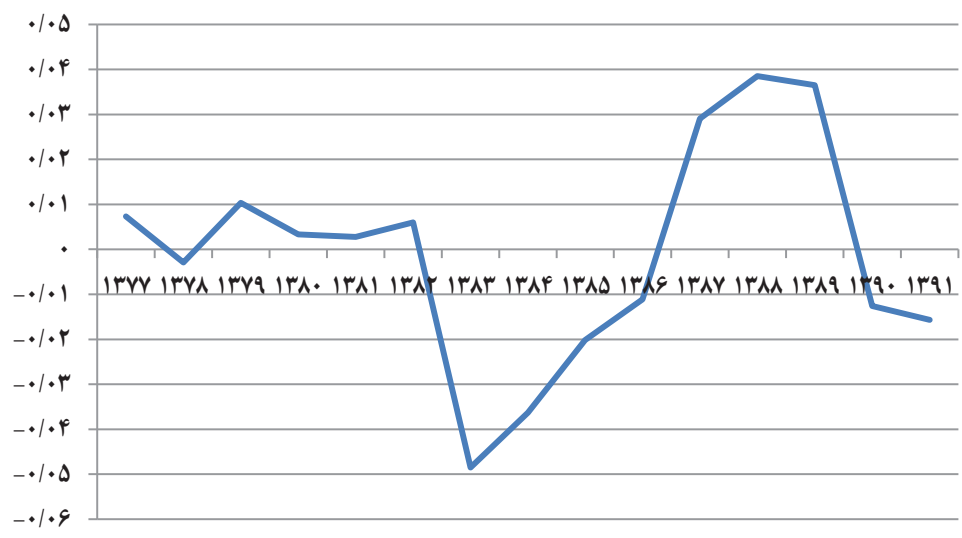




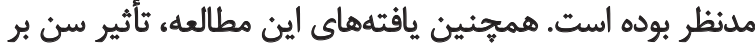

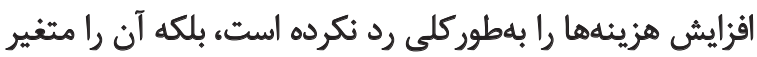

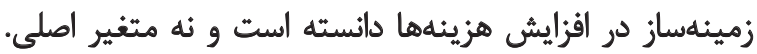

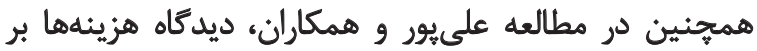

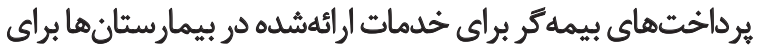

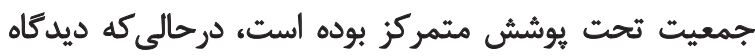

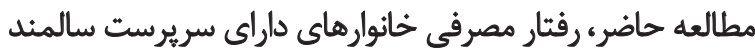
در مقايسه با خانوارهاي عادى بوده است.

\section{نتيجه تيرى نمبايى}

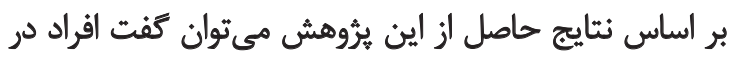

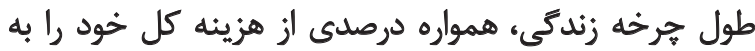

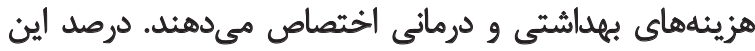
تخصيص در سنين مختلف متفاوت است، بلهنحوى كنه بان با افزايش

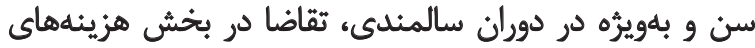

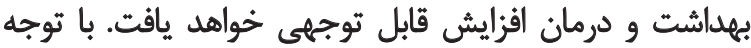

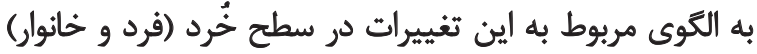

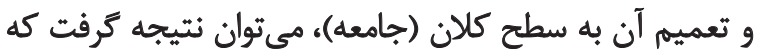

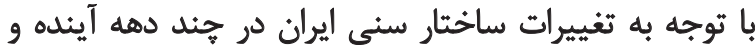

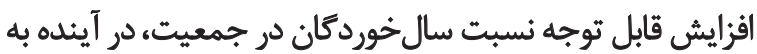

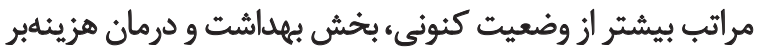

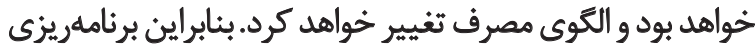
منسجم در اين زمينه ضرورى است.

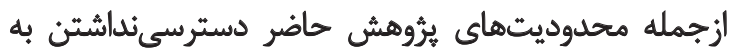

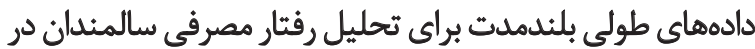

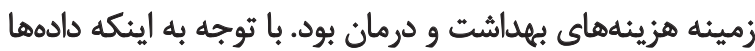

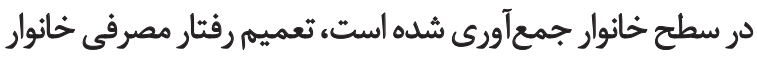

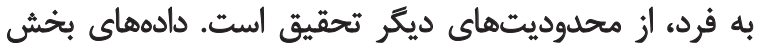

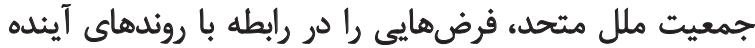

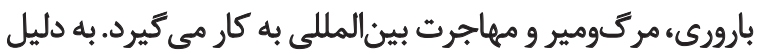

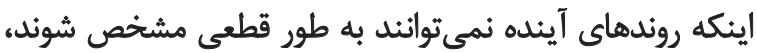

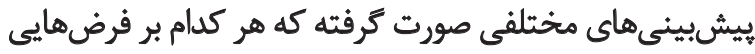

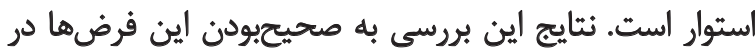

$$
\text { جمعيث ايران بستكى دارد. }
$$

تيشنهادمى شوددر يروهشهاى آتى نكات زير مدنظرقرار تيرد:

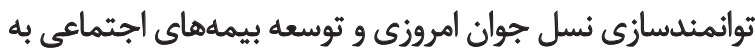

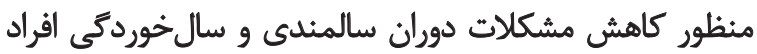

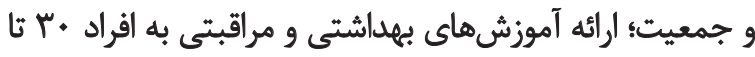

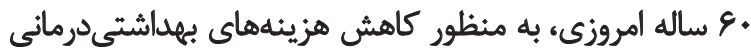

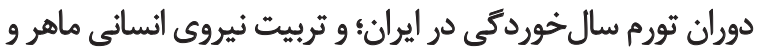

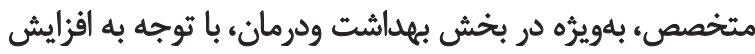

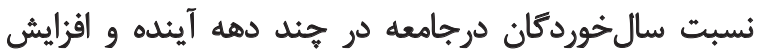
جشمعير تقاضا در اين بخش.
دوران سالمندى و هزينههاى مربوط به آن باشد.

نتايج مربوط به اثر سال (زمان) بر تثاضاى مصرف هزينهائ بناي

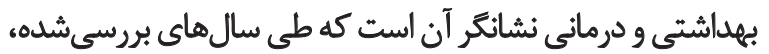

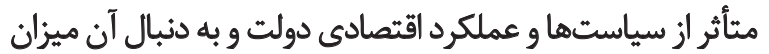

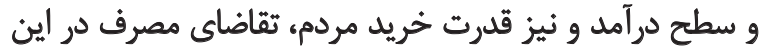

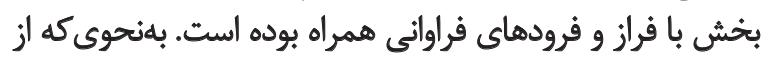

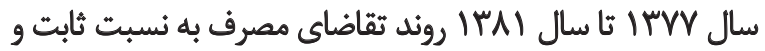

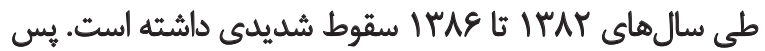

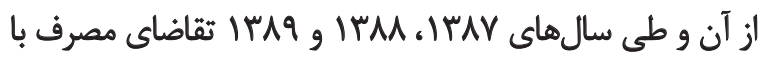

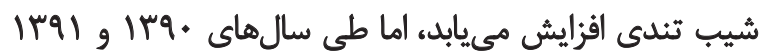

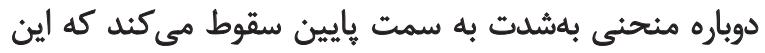

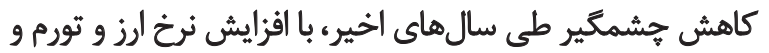

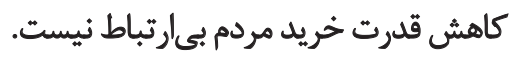

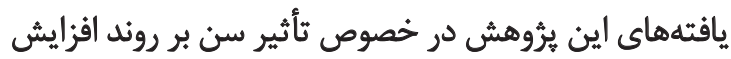

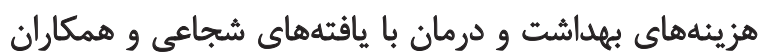

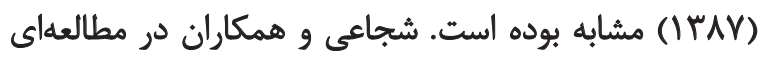

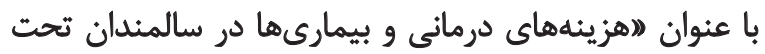

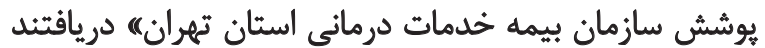

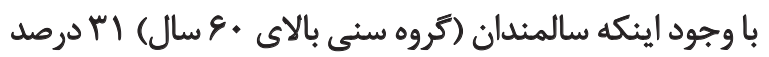

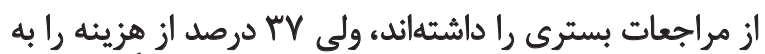

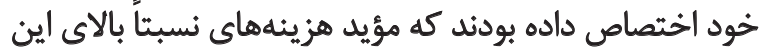

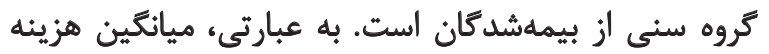

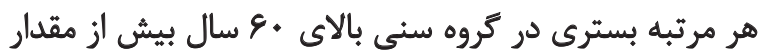

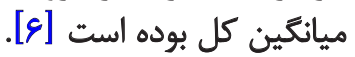

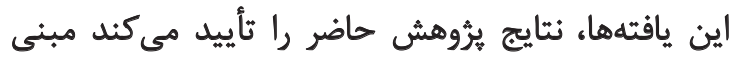

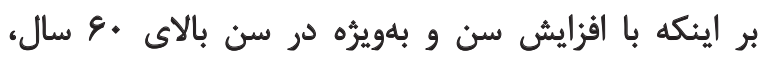

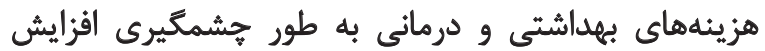

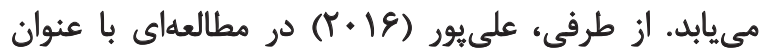

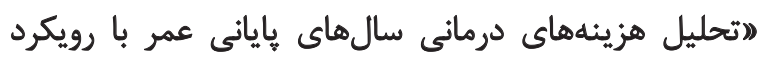

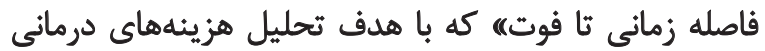

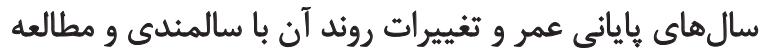

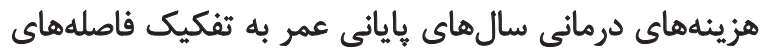

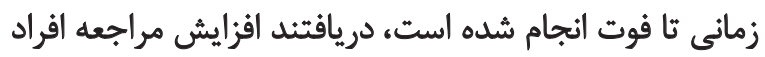

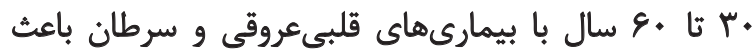

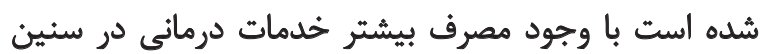

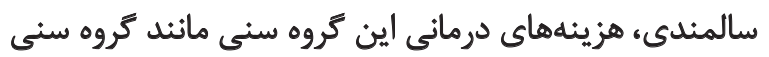

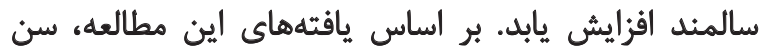

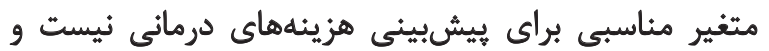

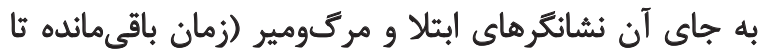

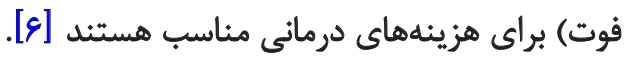

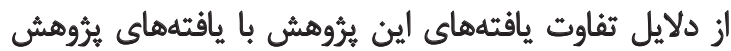

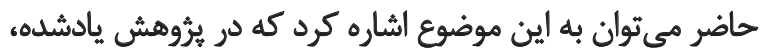

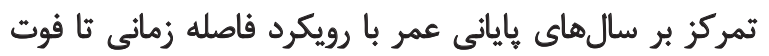




$$
\text { تشكر وقدرواني }
$$

اين مقاله از جاياننامه مقطع كارشناسى ارشد آقاى سعدالله

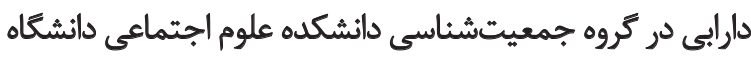
تهران ترفته شده است. 


\section{References}

[1] World Health Organization. Global health and ageing. Geneva: World Health Organization; 2011.

[2] Sadeghu R. [Population and development in Iran: Dimensions and challenges (Persian)]. Tehran: National Population Studies \& Comprehensive Management Institute; 2009.

[3] Darabi S, Torkashvand M, Latifi Gh. [Economic and social consequences of population aging in Iran 1950-2050 (Persian)]. Ketab-e Mah-e Oloum Ejtema'i. 2012; 16(58):17-28.

[4] Kinsella KG, Phillips DR. Global aging: The challenge of success. Washington, D.C.: Population Reference Bureau; 2005.

[5] Population Reference Bureau. World population data sheet. Washington, D.C.: Population Reference Bureau; 2010.

[6] Alipour V. [An analysis of the end of life medical expenditures with TTD approach: two part model and heckman sample selection (Persian)] [PhD thesis]. Tehran: Tehran University of Medical Sciences; 2016.

[7] Darabi S. [The effect of population aging on consumtion demand in urban regions of Iran, 1996-2012 (Persian)] [MSc. thesis]. Tehran: University of Tehran; 2013.

[8] United Nations. World population prospects: The 2015 revision. New York: United Nations; 2015.

[9] Deaton A. Panel data from time series of cross-sections. Journal of Econometrics. 1985; 30(1-2):109-26. doi: 10.1016/03044076(85)90134-4

[10] Statistical Center of Iran. [The raw of data of urban budget households over the period 1996-2012 (Persian)]. Tehran: Statistical Center of Iran; 2013.

[11] Deaton A, Paxson C. Intertemporal choice and inequality. Journal of Political Economy. 1994; 102(3):437-67. doi: 10.1086/261941

[12] Deaton A. The analysis of household Surveys. London: Johns Hopkins University Press; 1997.

[13] Saraei H, [Preliminary analysis techniques with emphasis on the distribution and composition of population age composition of the population (Persian)]. Tehran: Allameh Tabataba'i University; 2003. 